\title{
Sarcopenia Indicators as Predictors of Functional Decline and Need for Care among Older People.
}

\section{Björkman, M.}

2019

Björkman , M , Jyväkorpi , S K , Strandberg , T E , Pitkälä , K H \& Tilvis , R S 2019 , ' Sarcopenia Indicators as Predictors of Functional Decline and Need for Care among Older People. ' , Journal of nutrition, health \& aging , vol. 23 , no. 10 , pp. 916-922 . https://doi.org/10.1007/s12603-019-12

http://hdl.handle.net/10138/323900

https://doi.org/10.1007/s12603-019-1280-0

publishedVersion

Downloaded from Helda, University of Helsinki institutional repository.

This is an electronic reprint of the original article.

This reprint may differ from the original in pagination and typographic detail.

Please cite the original version. 


\title{
SARCOPENIA INDICATORS AS PREDICTORS OF FUNCTIONAL DECLINE AND NEED FOR CARE AMONG OLDER PEOPLE
}

\author{
M. BJÖRKMAN ${ }^{1}$, S.K. JYVÄKORPI ${ }^{2}$, T.E. STRANDBERG ${ }^{1}$, K.H. PITKÄLÄ², R.S. TILVIS ${ }^{1}$
}

1. University of Helsinki, Institute of Clinical Medicine, Department of Internal Medicine, Geriatric Unit, University of Helsinki, Finland; 2. University of Helsinki, Clinicum, and Helsinki University Hospital Unit of Primary health care, Finland. Corresponding author: Satu Jyväkorpi, Tukholmankatu 8, department of General Practice and Primary Health Care, Helsinki, Finland, satu.jyvakorpi@helsinki.fi, Tel: +358 504920970

\begin{abstract}
Objectives: Sarcopenia is associated with poor health outcomes. We examined the relative roles of muscle mass, strength, physical performance and obesity as health predictors among older sarcopenic people. Design and participants: This prospective study examined community-dwelling people aged $75+(\mathrm{N}=262)$. Setting: Porvoo Sarcopenia and Nutrition Trial. Measurements: We collected demographic data and medical history by postal questionnaire including RAND-36 at baseline and at four years and measured BMI, Short Physical Performace Battery (SPPB), hand-grip strength, cognition and two surrogate measures of muscle mass; the Single Frequency Skeletal Muscle Index (SF-SMI) and the Calf Intracellular Resistance Skeletal Muscle Index (CRi-SMI). Results: Adjusted for age and gender, independent outdoors mobility was predicted positively by baseline physical functioning scores in RAND-36 ( $<<0.001)$, the SPPB $(\mathrm{p}<0.001)$, the two-minute step test $(\mathrm{p}<0.001)$, and grip strength $(\mathrm{p}=0.023)$, as well as CRi-SMI $(\mathrm{p}<0.001)$. However, the prediction was negative in BMI $(p<0.001)$ and the Charlson co-morbidity Index $(p=0.004)$. Similar associations were found when the physical component RAND-36 was used as an outcome measure. The use of home care was predicted by high co-morbidity $(\mathrm{p}=0.057)$ and low scores in RAND-36 $(\mathrm{p}<0.001)$, SPPB $(\mathrm{p}<0.001)$ and the two-minute step test $(\mathrm{p}<0.001)$, and low CRi-SMI ( $<<0.001)$. CRi-SF was a more consistent predictor than SF-SMI, which was partly masked by BMI. Controlled for age, gender and comorbidity, a 10\% difference in CRi-SMI was associated with a $4 \%$ higher probability $(\mathrm{p}=0.019)$ of independently living at home, whereas the respective figures for SF-SMI and BMI were $-18 \%(\mathrm{p}=0.098)$ and $-14 \%(\mathrm{p}=0.088)$. Conclusions: In contrast to SF-SMI, high CRi-SMI appeared to indicate good prognosis and less need of care, independently of BMI.
\end{abstract}

Key words: Sarcopenia, muscle mass, muscle strength, activities of daily living, Bioimpedance analysis.

\section{Introduction}

Sarcopenia as a clinical syndrome has been described as low muscle strength and/or low muscle quality or quantity and poor physical performance (1-3). Depending on the definition, the prevalence of sarcopenia is reported to be up to $29 \%$ among older community-dwelling adults and up to $33 \%$ among individuals living in long-term care institutions (1-3). Several studies have linked sarcopenia as a clinical entity to morbidity and mortality, impaired physical disability, falls, fractures, poor quality of life, depression and hospitalization (4-11). In a recent review, sarcopenia, defined by computed tomography, was common among chronically ill hospital patients and associated with infectious complications, longer hospitalization, higher mortality and greater need for rehabilitation (12).

The relative role of various sarcopenic components as health predictors has raised discussion and clearly needs further evaluation. Special attention has been paid to the comparative importance of muscle loss and muscle function. Although both low muscle mass and poor muscle function predispose older adults to poor health outcomes, the associations of their components with aging differ $(13,14)$. Several studies have shown that mid-arm muscle and calf circumferences correlate with appendicular muscle mass and reflect both health and nutritional status and predict physical performance, health and survival among older people $(7,8,15,16)$. Clark and
Manini have emphasized that the loss of muscle function represents a greater risk of poor health outcomes and physical dependence than the loss of muscle mass and that monitoring muscle strength has greater feasibility in everyday practice (17). Some studies suggest that muscle function may be a more powerful predictor of disability and mortality than muscle mass $(18,19)$ and that reduced muscle quality has a greater impact on physical independence $(13,20,21)$. A recent, large crosssectional study associated low muscle mass with a risk of losing physical independence at 90 years of age, but the loss of muscle function played a more dominant role, and the presence of both criteria presented the greatest risk (22).

Simultaneous obesity or lack of obesity has also often confounded results. For instance, it has been suggested that obesity combined with poor muscle function, but not with low muscle mass, predicts the risk of falls at older ages (23). According to a review of 12 prospective cohort studies, sarcopenic obesity was associated with a $24 \%$ increased risk of all-cause mortality (24). However, in a recent English study, sarcopenic obesity did not confer any greater risk than sarcopenia alone (25). The greatest mortality was observed when sarcopenia was associated with weight loss.

Most characteristics of sarcopenia are relatively easy to measure and standardize. However, obtaining an accurate measure of muscle mass may be a major obstacle. Magnetic resonance imaging (MRI), computed tomography (CT) and 


\section{THE JOURNAL OF NUTRITION, HEALTH \& AGING@}

dual energy x-ray absorptiometry (DXA) are not often available for large-scale population studies (1). Transportable bioelectrical impedance analysis (BIA) estimates the volume of fat and lean body mass based on the relationship between the volume of a conductor and its electrical resistance. The method is not expensive, requires no specialized staff and is relatively easy to use in clinical practice, both on ambulatory subjects and hospitalized patients. Although the accuracy of the method has been criticized because it has been reported to overestimate muscle mass and underestimate fat mass (26-30), it can provide valid measurements (31). Bioimpedance spectroscopy (BIS) uses hundreds of frequencies within a wide range, allowing the calculation of intracellular resistance ( $\mathrm{Ri}$ ), a measure that does not require data on subject characteristics or population-based algorithms. $\mathrm{Ri}$ is closely related to the intracellular water (ICW) compartment and may be considered a surrogate for skeletal muscle cell mass, as fat and bone cells have low intracellular water content (26).

In order to obtain a deeper insight into the relative influences of sarcopenia indicators, it seems to be justifiable to simultaneously and repeatedly test all the characteristics of sarcopenia longitudinally, in sufficiently long-term studies with a large series of independent outcomes. For this purpose, we related measures of muscle mass, muscle strength, and physical functioning indices registered three times during the first year to the outcome four years later. We placed special emphasis on the predictive value of two bioimpedance measures of muscle biology.

\section{Methods}

\section{Participants}

The data were derived from the Porvoo Sarcopenia and Nutrition Trial (ACTRN12612001253897) (32). Briefly, we approached the $75+$ population living in Porvoo, Finland $(\mathrm{N}=3275)$ via a postal questionnaire (response rate $60.5 \%$ ), and the research group further examined the individuals at risk of sarcopenia (limitations in activities of daily living, sedentary lifestyle, falls, exhaustion, old age, low BMI) $(\mathrm{N}=428)$. Of these, 88 died within four years. A total of 182 randomized people participated in a three-armed, 12-month intervention trial and were re-examined at six months and at one year from baseline. Of these participants, 33 died before the four-year examination. We obtained the census status and date of death of the participants from the bureau of Official Statistics of Finland (SVT) in 2016, which is $100 \%$ complete.

\section{Data collection and examinations}

We collected demographic data and medical history by postal questionnaire at baseline and at four years. The response rate for the four-year postal questionnaire was $79.1 \%(\mathrm{~N}=262 / 340)$. The questionnaires included a Finnish translation of the physical functioning RAND-36 (0-100 points) (33). Morbidity was classified according to the Charlson
Comorbidity Index (CCI) (34).

The participants at risk of sarcopenia were examined clinically at a day clinic or during a home visit. We assessed physical performance using the short physical performance battery (SPPB) (35), with 0 points indicating poorest and 12 best performance. The tests included measurements of walking speed (36) and the chair-stand-test (37). Muscle strength was assessed using a hand grip dynamometer (JAMAR dynamometer, Saehan Corp., Masan, Korea). Cognitive function was evaluated by the Minimental State Examination (MMSE) (38), muscle endurance by the two-minute step test (39), and BMI was also calculated.

Bioimpedance spectroscopy was performed using a singlechannel, tetra polar device (SFB7, ImpediMed Ltd., Eight Miles Plains, Queensland, Australia) that scans 256 frequencies between 4 and $1000 \mathrm{kHz}$. We recorded the values without further software processing. Segmental calf intracellular resistance skeletal muscle index (CRi-SMI) was calculated from the BIS data of calf measurements as follows: CRiSMI=electrode distance2/Ricalf $(\mathrm{cm} 2 / \Omega)$, using the means of both calves. The whole-body single frequency skeletal muscle index (SF-SMI) was calculated from the whole-body skeletal muscle mass (SMM), assessed according to Janssen et al. [40]. It was then transformed into the skeletal muscle index as follows: SF-SMI=SMM/height ${ }^{2}$.

The survey elicited the use of home-care services.

\section{Ethics}

The study protocol was approved by the ethics committee for internal medicine of the hospital district of Helsinki and Uusimaa. We obtained informed consent from each patient or their next of kin. The participants signed their informed consent before the start of any trial procedures. In the case of a participants' cognitive decline $((\mathrm{MMSE})<19)(38)$ or poor capability of judgment, a proxy was invited to give consent in addition to the participant's consent.

\section{Statistics}

We used SPSS software (IBM Corp. Released 2012. IBM SPSS Statistics for Windows, Version 21.0. Armonk, NY: IBM Corp.) for the statistical analyses. Continuous variables with normal distribution were expressed by means with standard deviations (SD) and those with skewed distribution by medians with first and fourth quartile cut-off points. For the variables with normal distribution, we conducted statistical comparisons of the groups using Student's t-test, and for those with skewed distribution the Mann-Whitney $U$ test. When appropriate, we used analysis of variance. The Chi-Square test was used to test the relationship between the two categorical variables and Fischer's exact test was used when appropriate. We performed binary logistic regression analysis and linear regression analyses to assess the prognostic significance separately for each test variable. Age and gender were used as covariates. 


\section{SARCOPENIA INDICATORS AS PREDICTORS OF PHYSICAL FUNCTIONING}

Table 1

Baseline characteristics (SD) of participants of follow-up study $(\mathrm{N}=262)$ by gender and use of home care services at four years

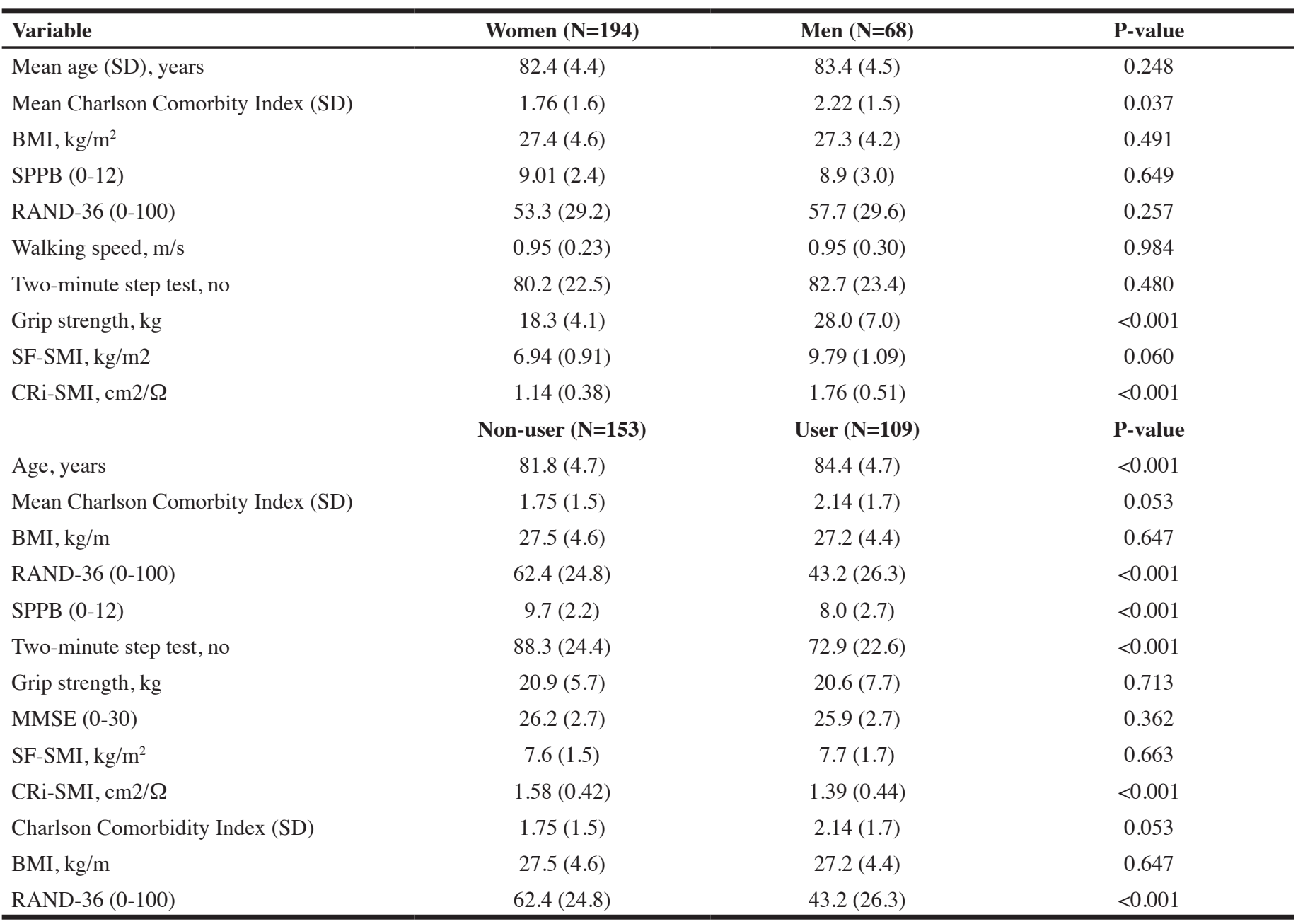

Tähän pitäisi laittaa variaabeleiden referenssit + statist. testit

\section{Results}

\section{Baseline characteristics}

Of the 428 participants clinically examined at entry, 88 died during the follow-up period. The mean age of the respondents was 83 years at entry. At four years, we sent a postal questionnaire to 340 survivors, which was returned by $262(79.1 \%)$. Compared with the women, the men had more diseases (higher comorbidity index) but greater muscle mass and strength (Table 1). Otherwise, the differences in age, BMI and physical functioning between the genders were insignificant.

Compared with the respondents, the non-respondents $(\mathrm{N}=78)$ were sicker (CCI 2.32 vs $1.88, \mathrm{p}=0.048$ ), and had poorer performance (SPPB 7.81 vs $8.97, \mathrm{p}<0.001$ ), and but their muscle mass SF-SMI $\left(8.16 \mathrm{~kg} / \mathrm{m}^{2}\right.$ vs $\left.7.67 \mathrm{~kg} / \mathrm{m}^{2}, \mathrm{p}=0.022\right)$ was higher at baseline. These differences were mainly due to men being over-presented among the non-respondents $(30.0 \%$ vs
$20.1 \%, \mathrm{p}=0.054)$.

\section{Follow-up}

The majority $(\mathrm{N}=252,96 \%)$ of the participants still lived at home and 153 people $(58.4 \%)$ did not use home care services at four years (Table 1$)$. Three out of four $(72.1 \%)$ complained of memory decline. Most $(\mathrm{N}=185,70.6 \%)$ did not use walking aids indoors and one in two (51.5\%) were able to walk outdoors without aids or help. A total of $32(12 \%)$ people were not able to get up from a chair without assistance (hands or other person) and $17(7 \%)$ did not walk outdoors at all. Of the respondents, 98 (37\%) had fallen and $15(6 \%)$ had suffered a bone fracture during the previous year. Fifty-eight $(22 \%)$ reported a weight loss of at least $3 \mathrm{~kg}$ during the previous three months but only $26(10 \%)$ regarded their general health as poor. 
Table 2

Age- and gender-adjusted predictors of good outdoor mobility (no aids and no help)

\begin{tabular}{lccc}
\hline Variable & OR & $\mathbf{9 5 \%}$ CIs & P-value \\
\hline BMI, $\mathrm{kg} / \mathrm{m}^{2}$ & 0.88 & $0.83-0.94$ & $<0.001$ \\
Baseline RAND-36 (0-100) & 1.05 & $1.04-1.06$ & $<0.001$ \\
Charlson comorbidity Index & 0.76 & $0.63-0.92$ & 0.004 \\
SPPB (1-12) & 1.67 & $1.43-1.97$ & $<0.001$ \\
Two-min step test. no & 1.03 & $1.02-1.04$ & $<0.001$ \\
Grip strength. kg & 1.07 & $1.01-1.13$ & 0.023 \\
SF-SMI, kg/m & 0.74 & $0.55-0.98$ & 0.036 \\
CRi-SMI, cm2/ $\Omega$ & 2.40 & $1.16-5.01$ & 0.009 \\
\hline
\end{tabular}

Age and gender were forced into logistic regression analysis as covariates.

Table 3

Test variables measured during one year as age- and gender-adjusted predictors of RAND-36 index four years later

\begin{tabular}{llccc}
\hline Variable & & Standardized beta & 95\% CI for beta & P-Value \\
\hline Charlson comorbidity index & Baseline & -0.10 & $-2.23-0.09$ & 0.034 \\
SPPS (0-12) & Baseline & 0.33 & $1.73-3.14$ & $<0.001$ \\
& 6 months & 0.26 & $1.85-3.84$ & $<0.001$ \\
& 12 months & 0.288 & $2.11-4.04$ & $<0.001$ \\
BMI, kg/m ${ }^{2}$ & Baseline & -0.21 & $-2.05-0.60$ & $<0.001$ \\
& 6 months & -0.17 & $-2.36-0.04$ & 0.043 \\
Two-minute step test. no & 12 months & -0.15 & $-2.24-0.10$ & 0.072 \\
& Baseline & 0.34 & $0.26-0.39$ & $<0.001$ \\
Grip strength. kg & 6 months & 0.22 & $0.17-0.41$ & $<0.001$ \\
& 12 months & 0.23 & $0.18-0.42$ & $<0.001$ \\
Baseline & 0.16 & $0.09-0.88$ & 0.016 \\
& 6 months & 0.19 & $-0.08-2.07$ & 0.070 \\
& 12 months & 0.24 & $0.11-2.10$ & 0.014 \\
CRi-SMI, cm2/ $\Omega$ & Baseline & -0.22 & $-7.46--0.51$ & 0.025 \\
& 6 months & -0.20 & $-9.66-2.27$ & 0.222 \\
& 12 months & -0.32 & $-11.62--0.17$ & 0.044 \\
& Baseline & 0.08 & $-3.25-13.72$ & 0.226 \\
\hline
\end{tabular}

Age and gender were forced into linear regression analysis as covariates.

\section{Predictors of physical functioning}

Those living independently at four years had lower baseline BMI (26.9 vs 29.3 , gender adjusted $\mathrm{p}=0.029)$, and lower SF-SMI $\left(7.53 \mathrm{~kg} / \mathrm{m}^{2}\right.$ vs $\left.7.96 \mathrm{~kg} / \mathrm{m}^{2}, \mathrm{p}=0.039\right)$ but higher CRiSMI $(1.56 \mathrm{~cm} 2 / \Omega$ vs $1.38 \mathrm{~cm} 2 / \Omega, \mathrm{p}=0.010)$ than the other participants.

The predictive value of the various sarcopenia indicators was first tested in relation to outdoor mobility. Table 2 shows that good physical functioning according to RAND-36, good physical performance according to SPPB, and good walking speed and muscle strength at baseline predicted good outdoor mobility in the follow-up, and that obesity and comorbidity had opposite relationships. The muscle mass indicators showed different results: CRi-SMI was a strong predictor of good 
SARCOPENIA INDICATORS AS PREDICTORS OF PHYSICAL FUNCTIONING

Table 4

Age- and gender-adjusted predictors of use of home care services

\begin{tabular}{lccc}
\hline Variable & OR & 95\% CIs & P-value \\
\hline Baseline RAND-36 (0-100) & 0.97 & $0.96-0.98$ & $<0.001$ \\
Charlson comorbidity Index & 1.17 & $0.99-1.38$ & 0.057 \\
SPPB (1-12) & 0.79 & $0.70-0.88$ & $<0.001$ \\
Two-minute step test. no & 0.98 & $0.97-0.99$ & $<0.001$ \\
CRi-SMI, $\mathrm{cm}^{2} / \Omega$ & 0.37 & $0.18-0.74$ & $<0.001$ \\
\hline
\end{tabular}

Age and gender were forced into logistic regression analysis as covariates.

Table 5

Comparison of BMI and skeletal muscle indices as predictors of physical functioning at four-year follow-up

\begin{tabular}{|c|c|c|c|c|c|c|}
\hline \multirow[t]{2}{*}{ Variable } & \multicolumn{3}{|c|}{ At home without helps ${ }^{a}$} & \multicolumn{3}{|c|}{ Physical functioning of RAND-36 ${ }^{b}$} \\
\hline & OR & 95\% CIs & P-value & Standardized beta & $95 \%$ CI for beta & P-value \\
\hline \multicolumn{7}{|c|}{ Unadjusted } \\
\hline $\mathrm{BMI}, \mathrm{kg} / \mathrm{m}^{2}$ & 0.94 & $0.88-0.99$ & 0.031 & -0.21 & $-2.09-0.56$ & $<0.001$ \\
\hline SF-SMI, $\mathrm{kg} / \mathrm{m}^{2}$ & 0.84 & $0.71-0.99$ & 0.045 & -0.03 & $-2.88-1.62$ & 0.584 \\
\hline CRi-SMI, $\mathrm{cm}^{2} / \Omega$ & 2.52 & $1.32-4.83$ & 0.005 & 0.16 & $2.33-18.9$ & 0.011 \\
\hline \multicolumn{7}{|c|}{ Adjusted for age and gender } \\
\hline $\mathrm{BMI}, \mathrm{kg} / \mathrm{m}^{2}$ & 0.93 & $0.88-0.99$ & 0.025 & -0.20 & $-2.01-0.56$ & $<0.001$ \\
\hline SF-SMI & 0.74 & $0.55-0.98$ & 0.036 & -0.21 & $-7.31--9.38$ & 0.030 \\
\hline CRi-SMI, $\mathrm{cm}^{2} / \Omega$ & 2.41 & $1.16-5.01$ & 0.019 & 0.07 & $-4.10-13.01$ & 0.306 \\
\hline \multicolumn{7}{|c|}{ Adjusted for age, gender and comorbidity } \\
\hline BMI, $\mathrm{kg} / \mathrm{m}^{2}$ & 0.95 & $0.89-1.01$ & 0.088 & -0.18 & $-1.86--0.39$ & 0.003 \\
\hline SF-SMI, $\mathrm{kg} / \mathrm{m}^{2}$ & 0.79 & $0.058-1.05$ & 0.098 & -0.17 & $-6.61-0.37$ & 0.079 \\
\hline CRi-SMI, $\mathrm{cm}^{2} / \Omega$ & 2.43 & $1.16-5.13$ & 0.019 & 0.07 & $-4.11-12.77$ & 0.314 \\
\hline \multicolumn{7}{|c|}{ Adjusted for age, gender, comorbidity and BMI } \\
\hline SF-SMI, $\mathrm{kg} / \mathrm{m}^{2}$ & 0.86 & $0.60-1.24$ & 0.412 & -0.01 & $-4.37-4.10$ & 0.951 \\
\hline CRi-SMI, $\mathrm{cm}^{2} / \Omega$ & 3.47 & $1.55-7.76$ & 0.002 & 0.15 & $1.07-18.63$ & 0.028 \\
\hline
\end{tabular}

a. Binary logistic regression analysis. b. Linear regression analysis.

outdoor mobility $(\mathrm{OR}=2.40)$, whereas the association with SF-SMI was significantly negative $(\mathrm{OR}=0.74, \mathrm{p}=0.036)$. When these measures were further adjusted for BMI, the predictive value of SF-SMI was $0.84(\mathrm{p}=0.34)$ and that of CRiSMI rose to $3.62(\mathrm{p}<0.001)$ (Table 2$)$.

We then tested the associations between potential baseline predictors and the physical component of RAND-36 at four years. We used age and gender as confounders in the linear regression analysis (Table 3). Again, good physical functioning was predicted by higher baseline SPPB, faster walking speed, and stronger hand grip, whereas higher BMI and higher muscle mass according to SF-SMI were associated with lower RAND36 scores. We found no association between baseline CRi-SMI and RAND-36 score at four years. However, when the effects of muscle mass indices were further adjusted for BMI, the negative predictive values of SF-SMI disappeared, and those of CRi-SMI became positive (standardized beta $=0.18, \mathrm{p}=0.011$ ). The results were consistent for all three measurements during one year. (Table 3)

\section{Use of services}

At four years, 69 (26\%) people (33 men and 36 women) regularly used either municipal or private home care services. These users were older, had more diseases and reported poorer physical functioning than the non-users. Neither the grip strength nor the muscle mass indictor SF-SMI of the groups differed, but CRi-SMI was lower among the users than the non-users. The significance of the differing characteristics was tested more closely using binary logistic regression analysis, which used age and gender as covariates (Table 4). Again, 


\section{THE JOURNAL OF NUTRITION, HEALTH \& AGING@}

the indicators of good physical functioning and performance (RAND-36, SPPB) and good mobility retained highly significant predictive value. This also held true for CRi-SMI.

\section{Figure 1}

Probability of independently living at home by $10 \%$ differences in muscle mass indices (CRI-SMI and SF-SMI) and body mass index (BMI). The data are adjusted for age, gender and comorbidity

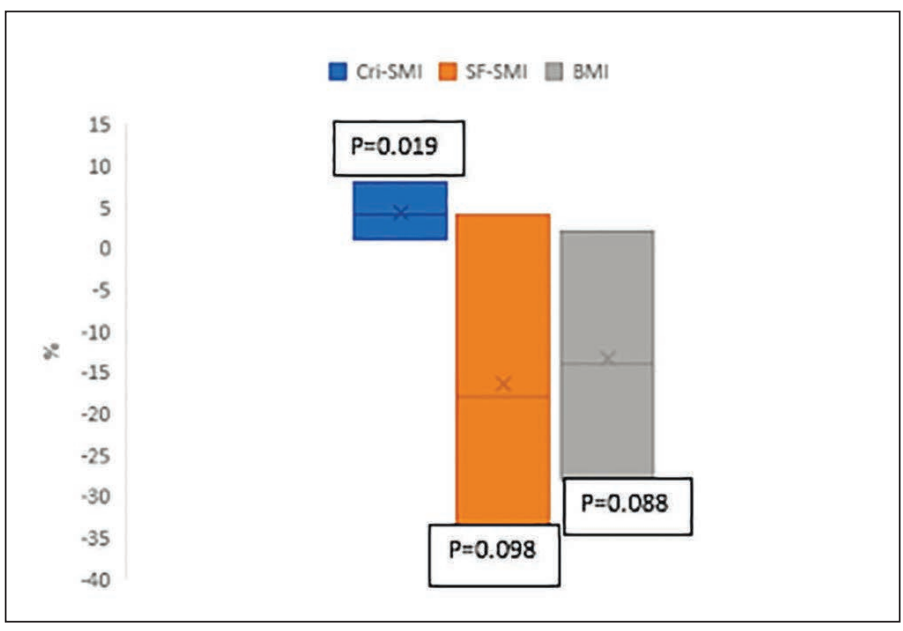

\section{Comparison of BMI and skeletal muscle indices}

Finally, we compared the predictive values of BMI and two skeletal muscle indices in relation to the use of help and physical functioning (Table 5). Again, both BMI and SF-SMI were negatively associated and CRi-SMI positively associated with the prognosis of physical functioning according to RAND36. When adjusted for age, gender and comorbidity, the negative influence of BMI remained virtually unchanged, but the positive association with CRi-SMI accentuated. The latter was also highly predicted after further controlling for BMI. Due to the large differences in the scales of BMI and muscle mass measures, we used percentage distributions $($ mean $=100$ ) for further comparisons (Fig. 1). When controlled for age, gender and comorbidity, a $10 \%$ difference in Cri-SMI was associated with a $4 \%$ better probability of independently living at home, whereas the respective figures for SF-SMI and BMI were - $18 \%$ and $-14 \%$.

\section{Discussion}

This longitudinal study shows that good baseline physical performance and functioning, stronger hand grip strength, higher muscle mass indices and lower BMI predict better physical performance and the need for care of older people at risk of sarcopenia. We also found interesting differences in the predictive significance of various methods in the assessment of muscle mass.

The results do not challenge earlier observations concerning obesity or hand grip strength (41) but provide new insights into the differences of the two muscle mass indices and their interplay with BMI. Both high BMI and high SF-SMI predicted consistently poorer outcomes, whereas high CRi-SMI was associated with good mobility and physical functioning and predicted independent living at home. In this respect, the contradictory results of CRi-SMI and SF-SMI deserve special attention. Closer analyses revealed a relatively strong positive correlation between BMI and SF-SMI (age- and gender adjusted rho $=0.573, \mathrm{p}<0.001$ ) at baseline (unpublished data). Thus, the clearly negative influence of high BMI overruns the possible beneficial effects of whole-body muscle mass measured by SF-SMI in this population sample. This was, in fact, verified by adjusting the effects of muscle mass indices for BMI, which partly abolished the negative associations of SF-SMI and accentuated the positive associations of CRi-SMI. The observation that high BMI and low CRi-SMI were both strong, independent predictors of poor physical functioning in old age accord well with the concept of sarcopenic obesity, which has become increasingly important in the aging population $(24,25,42)$. Evidence is also increasing that sarcopenic obesity is also associated more with mortality and cardiovascular risk factors than with sarcopenia or obesity alone $(24,26,44)$.

The study clearly showed the superiority of CRi-SMI over SF-SMI as a positive mobility predictor among older people. This observation is not surprising, as the former measures the muscle mass of the lower limbs, whereas the latter reflects whole-body muscle mass. It is conceivable that the lower-limb muscles are more important for mobility than whole-body muscle mass. The present results accord well with earlier observations that have shown close associations between CriSMI and the daily living activities and mobility of typical nursing home residents (44). Our observations also support the criticism of the validity of SF-SMI measurements of older people (26-30).

The representativeness of the population sample, the serial measures of the key indicators, the clear end-points and the consistency of the results are this study's major strengths. Its weaknesses are its lacking DEXA or MRI measurements.

Conclusion Lower limb CRi-SMI is an independent longterm predictor of the outdoor mobility and physical functioning of older sarcopenic home-dwelling people, whereas the predictive value remains insignificant for whole-body muscle mass index (SF-SMI), which is partly masked by negative influences of high BMI.

Acknowledgements: This study is funded by the University of Helsinki, Konung Gustav V:s och Drottning Victorias Frimurarestiftelse, the Yrjö Jahnsson Foundation, and Valio Ltd. The co-operation of Porvoo municipal health care services is greatly appreciated.

Conflicts of interest: Dr Mikko Björkman reports professional cooperation including lecturing fees from Valio Ltd, Nestle Health Science Ltd. and Nutricia Medical Ltd., Dr Timo Strandberg reports having various educational and consultative cooperation with several companies, including Nutricia, Abbott, Amgen, Merck, Pfizer, Novartis, and NovoNordisk; a minor amount of stock in Orion Pharma; and is a board member and former president of executive board of European Union Geriatric Medicine Society which has cooperation also with the nutrition industry. Drs Satu Jyväkorpi, Kaisu Pitkala and Dr Reijo Tilvis have no competing interests. 


\section{SARCOPENIA INDICATORS AS PREDICTORS OF PHYSICAL FUNCTIONING}

\section{References}

1. Cruz-Jentoft AJ, Bahat G, Bauer J et al. Writing Group for the European Working Group on Sarcopenia in Older People 2 (EWGSOP2), and the Extended Group for EWGSOP2. Sarcopenia: revised European consensus on definition and diagnosis. Age Ageing 2019;48(1):16-31. doi: 10.1093/ageing/afy169 2.

2. Marzetti E, Calvani R, Tosato M et al. Sarcopenia: an overview. Aging Clin Exp Res 2017;Feb;29(1):11-17. doi: 10.1007/s40520-016-0704-5. Epub 2017 Feb 2.

3. Bischoff-Ferrari HA, Orav JE, Kanis JA et al. Comparative performance of current definitions of sarcopenia against the prospective incidence of falls among community dwelling seniors age 65 and older. Osteoporos Int 2015;26(12):2793-802.doi:10.1007/ s00198-015-3194-y.

4. Lauretani F, Russo CR, Bandinelli S et al. Age-associated changes in skeletal muscles and their effect on mobility: an operational diagnosis of sarcopenia. J Appl Physiol 2003;95:1851-1860

5. Visser M, Schaap LA. Consequences of sarcopenia. Clin Geriatr Med 27:387-399

6. Lang T, Steeper T, Cawthon P et al. Sarcopenia: etiology, clinical consequences, intervention, and assessment. Osteoporos Int 2010;21:543-59. doi: 10.1007/s00198009-1059-y. Epub 2009 Sep 2

7. Landi F, Russo A, Liperoti R, et al. Midarm muscle circumference, physical performance and mortality: results from the aging and longevity study in the Sirente geographic area (ilSIRENTE study). Clin Nutr. 2010;29:441-447

8. Landi F, Liperotti R, Russo A et al. Sarcopenia as a risk factor for falls in elderly individuals: results from the ilSIRENTE study. Clin Nutr 2012;31:652-658 doi: 10.1016/j.clnu.2012.02.007. Epub 2012 Mar 11.

9. Rizzoli R, et al. Quality of life in sarcopenia and frailty. Calcif Tissue Int 2013;93:101-120

10. Beaudart C, Rizzoli R, Bruyere O, Reginster JY, Biver E. Sarcopenia: Burden and challenges for Public Health. Arch Public Health 2014;72:45, doi: 10.1186/2049-3258 72-45. eCollection 2014

11. Landi F, Liperoti R, Fusco D, et al. Sarcopenia and mortality among older nursing home residents. J Am Med Dir Assoc 2012;13:121-126

12. Petersen SJ, Braunschweig CA. Prevalence of sarcopenia and associated outcomes in the clinical setting. Nutr Clin Pract 2016;31:40-48

13. Mitchell WK, Williams J, Atherton P, Larvi M, Lund J, Narici M. Sarcopenia, dynapenia, and the impact of advancing age on human skeletal muscle size and strength; a quantitative review. Front Physiol 2012;3:260. doi: 10.3389/ fphys.2012.00260. eCollection 2012.

14. da Silva AT, de Oliveira Duarte YA, Ferreira Santos JL, Wong R, Lebrão ML. Sarcopenia according to the European Working Group on Sarcopenia in Older People (EWGSOP) versus dynapenia as a risk factor for mortality in the elderly. J Nutr Health Aging. 2014; 18:751-6.

15. Rolland Y, Louwers-Cances V, Cournot M et al. Sarcopenia, calf circumference, and physical function of elderly women: a cross-sectional study. J Am Geriatr Soc. 2003;51:1120-1124

16. Landi F, Onder G, Russo A et al. Calf circumference, frailty and physical performance among older adults living in the community. Clin Nutr. 2014;33:539-544

17. Clark BC, Manini TM. Sarcopenia =/=dynapenia. J Gerontol A Biol Sci Med Sci 2008;63:829-834

18. Rantanen T. Muscle strength, disability and mortality. Scand J Med Sci Sports 2003;13: 3-8

19. Goins RT, Pignataro RM, Dong L, Rogers JC. Handgrip strength among older American Indians: the Native Elder Care Study. Age Ageing 2011;40:523-527

20. Venturelli M, Saggin P, Muti E, Naro F,Cancellara L, Toniolo L, et al. In vivo and in vitro evidence that intrinsic upper- andlower-limb skeletal muscle function is unaffected by ageing and disuse in oldest old humans. Acta Physiol (Oxf) 2015; doi:10.1111/apha.12524.

21. Grounds MD, Pinniger GJ. What is the mechanism for in vivo loss of skeletal muscle function in elderly females? Acta Physiol (Oxf) 2015;doi:10.1111/apha.12547.

22. dos Santos L, Cyrino ES. Antunes M, Santos DA, Sardinha LB. Sarcopenia and physical independence in older adults; the independence and synergic role of muscle mass and muscle function. J Cachexia, Sarcopenia and Muscle, 2016;DOI: 10.1002/ jesm. 12160

23. Scott D , Hayes A, Sanders KM, Aitken D, Ebeling PR, Jones G. Operational definitions of sarcopenia and their associations with 5-year changes in falls risk in community-dwelling middle-aged and older adults. Osteoporos Int. 2014;25(1):187-93 doi: 10.1007/s00198-013-2431-5. Epub 2013 Jun 26.
24. Tian S, Xu Y. Association of sarcopenic obesity with the risk of all-cause mortality: A meta-analysis of prospective cohort studies. Geriatr Gerontol Int. Feb;2016;16(2):15566. doi: 10.1111/ggi.12579. Epub 2015 Aug 14.

24. Hamer M, O'Donovan G. Sarcopenic obesity, weight loss, and mortality: the English Longitudinal Study of Ageing. Am J Clin Nutr. 2017;Jul;106(1):125-129. doi: 10.3945/ajen.117.152488. Epub 2017 May 24.

26. Yamada Y, Schoeller DA, Nakamura E, Morimoto T, Kimura M, Oda S. Extracellula water may mask actual muscle atrophy during aging. J Gerontol A Biol Sci Med Sci 2010;65:510-516

27. Yamada Y, Watanabe Y, Ikenaga M, Yokoyama K, Yoshida T, Morimoto T, Kimura $\mathrm{M}$. Comparison of single- or multifrequency bioelectrical impedance analysis and spectroscopy for assessment of appendicular skeletal muscle in the elderly. J Appl Physiol 2013;115:812-818

28. Yamada Y, Matsuda K, Björkman MP, Kimura M. Application of segmental bioelectrical impedance spectroscopy to the assessment of skeletal muscle cell mass in elderly men. Geriatr Gerontol Int 2014;14 Suppl 1: 129-134

29. Kim M, Kim H. Accuracy of segmental multi-frequency bioelectricalimpedance analysis for assessing whole-body and appendicular fat mass and lean soft tissue mass in frail women aged 75 years and older. Eur J Clin Nutr 2013;67:395-400.

30. Kim M, Shinkai S, Murayama H, Mori S. Comparison of segmental multifrequency bioelectrical impedance analysis with dual-energy X-ray absorptiometry for the assessment of body composition in a community dwelling older population. Geriatr Gerontol Int 2015;5:1013-1022

31. Buckinx F, Reginster JY, Dardanne N et al. Concordance between muscle mass assessed by bioelectrical impedance analysis and by dual energy X-ray absorptiometry: across-sectional study. BMC Musculoskelet Disord Mar 2015;18;16:60. doi: 10.1186/s12891-015-0510-9

32. Bjorkman MP, Suominen MH, Pitkälä KH, Finne-Soveri HU, Tilvis RS. Porvoo sarcopenia and nutrition trial: effects of protein supplementation on functional performance in home-dwelling sarcopenic older people - study protocol for a randomized controlled trial. Trials 2013;14:387. doi: 10.1186/1745-6215-14-387

33. Hays RD, Sherbourne CD, Mazel RM. The RAND 36-Item Health Survey 1.0. Health Econ, 1993

34. Charlson ME, Pompei P, Ales KL, MacKenzie CR. A new method of classifying prognostic comorbidity in longitudinal studies: development and validation. J Chronic Dis $1987: 40: 373-383$

35. Guralnik JM, Simonsick EM, Ferrucci L, Glynn RJ, Berkman LF, Blazer DG, Scherr PA, Wallace RB. A short physical performance battery assessing lower extremity function: association with self-reported disability and prediction of mortality and nursing home admission. J Gerontol 1994;49:M85-94

36. Working Group on Functional Outcome Measures for Clinical Trials. Functional outcomes for clinical trials in frail older persons: time to be moving. J Gerontol A Bio Sci Med Sci 2008;63:160-64

37. Takai Y, Ohta M, Akagi R, Kanehisa H, Kawakami Y, Fukunaga T. Sit-to-stand test to evaluate knee extensor muscle size and strength in the elderly: a novel approach. J Physiol Anthropol 2009;28:123-128

38. Folstein MF, Folstein SE, McHugh PR."Mini-mental state". A practical method for grading the cognitive state of patients for the clinician. J Psychiatr Res 1975;12:189 198

39. Rikli RE, Jones CJ. Development and validation of criterion-referenced clinically relevant fitness standards for maintaining physical independence in later years. Gerontologist. 2013;53:255-267.

40. Janssen I, Heymsfield SB, Baumgartner RN, Ross R. Estimation of skeletal muscle mass by bioelectrical impedance analysis. J Appl Physiol 2000;89:465-471

41. Bohannon RW. Muscle strength: clinical and prognostic value of hand-grip dynamometry. Curr Opin Clin Nutr Metab Care. 2015;Sep;18(5):465-470

42. Baumgartner RN. Body composition in healthy aging. Ann N Y Acad Sci 2000;904:437-448

43. Stenholm S, Harris TB, Rantanen T, Visser M, Kritchevsky SB, Ferrucci L. Sarcopenic obesity: definition, cause and consequences. Curr Opin Clin Nutr Metab Care 2008;11:693-700

44. Björkman MP, Finne-Soveri H, Pilvi TK, Tilvis RS. Bioimpedance spectroscopy as a measure of physical functioning in nursing home residents. Aging Clin Exp Res 2012;24:612-618 